See discussions, stats, and author profiles for this publication at: https://www.researchgate.net/publication/348575290

\title{
Organic sensitization of graphene oxide and reduced graphene oxide thin films for photovoltaic applications
}

Article in International Journal of Energy Research · December 2020

DOI: 10.1002/er.6414

\section{CITATIONS}

17 authors, including:

Muhammad Kashif

Tianjin University

100 PUBLICATIONS 1,390 CITATIONS

SEE PROFILE

Awais Ahmad

University of Lahore

35 PUBLICATIONS 74 CITATIONS

SEE PROFILE
READS

54

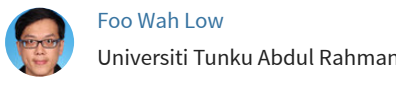

41 PUBLICATIONS 239 CITATIONS

SEE PROFILE

Zainab Ngaini

University Malaysia Sarawak

144 PUBLICATIONS 804 CITATIONS

SEE PROFILE

Some of the authors of this publication are also working on these related projects:

Project Semiconductor materials for water splitting View project

Hydrogel Scaffold-Based Fiber Composites for Engineering Applications 15.1 Introduction 15.1.1 Hydrogels View project 


\title{
Organic sensitization of graphene oxide and reduced graphene oxide thin films for photovoltaic applications
}

\author{
Muhammad Kashif ${ }^{1}$ (1) | Erdawaty Jafaar ${ }^{2}$ | Siti K. Sahari ${ }^{2} \quad$ Foo W. Low ${ }^{3}$ () | \\ Nguyen D. Hoa ${ }^{4}$ | Awais Ahmad ${ }^{5}$ | Anees Abbas ${ }^{6}$ | Zainab Ngaini ${ }^{7}$ | \\ Muhammad Shafa $^{8}$ | Ahsanulhaq Qurashi $^{9}$
}

${ }^{1}$ School of Electrical and Information Engineering, Tianjin University, Tianjin, Nankai, China

${ }^{2}$ Department of Electrical and Electronic, Faculty of Engineering, Universiti Malaysia Sarawak, Kota Samarahan, Sarawak, Malaysia

${ }^{3}$ Department of Electrical \& Electronic Engineering, Lee Kong Chian Faculty of Engineering \& Science, Universiti Tunku Abdul Rahman, Kajang, Malaysia

${ }^{4}$ International Training Institute for Materials Science (ITIMS), Hanoi University of Science and Technology (HUST), Hanoi, Vietnam

${ }^{5}$ Department of Chemistry, The University of Lahore, Lahore, Pakistan

${ }^{6}$ Department of Chemistry, University of Mianwali, Mianwali, Pakistan

${ }^{7}$ Faculty of Resource Science and Technology, Universiti Malaysia Sarawak, Kota Samarahan, Sarawak, Malaysia

${ }^{8}$ State Key Laboratory for Mechanical Behavior Materials, Xian Jiaotong, University, Xian, Shaanxi, China

${ }^{9}$ Department of Chemistry, Khalifa University, Abu Dhabi, United Arab Emirates

\section{Correspondence}

Muhammad Kashif, School of Electrical and Information Engineering, Tianjin University 92 Weijin Road, Nankai District, Tianjin 300072, China. Email: mkashif@tju.edu.cn

Siti K. Sahari, Department of Electrical and Electronics Engineering, Faculty of Engineering, Universiti Malaysia Sarawak, 94300 Kota Samarahan, Sarawak.

Email: sskudnie@unimas.my

\section{Summary}

In this work, a new organic compound (K-Azo) was introduced to enhance the electrical and optical performance of graphene oxide (GO) and reduced GO (rGO) nanostructured films. The improved and modified chemical vapour method was employed for the synthesis of GO and rGO. The photophysical characterization of thin films was performed by applying analytical techniques including X-ray diffraction, Fourier-transform infrared spectroscopy, scanning electron microscopy, ultraviolet-visible, and Raman spectroscopy. The electrical properties (I-V characteristic) of GO and rGO thin films displayed higher conductivity which was $4.07 \times 10^{-7}$ and $1.10 \times 10^{-3} \mathrm{~S} / \mathrm{cm}$, respectively in the presence of organic sensitizer. However, GO and rGO thin films showed 9.91 $\times 10^{-7}$ and $6.17 \times 10^{-4} \mathrm{~S} / \mathrm{cm}$, respectively in the absence of K-Azo sensitizer. Optical and electrical investigations indicated that the characteristics of GO and rGO were improved due to the presence of organic sensitizer. The longrange $\pi$-electron delocalization in organic sensitizer contributed to higher conductivity for potential photovoltaic solar cell applications.

\section{KEYWOR D S}

electrical properties, graphene oxide (GO), organic sensitizer, optical properties, photovoltaic (PV), reduced graphene oxide (rGO), solar cells 